\title{
Measurement of fish target strength with a split-beam echo sounder
}

Kenneth G. Foote, Asgeir Aglen, and Odd Nakken

Institute of Marine Research, 5011 Bergen, Norway

(Received 17 November 1985; accepted for publication 10 April 1986)

Data derived with a 38-kHz split-beam echo sounder have been analyzed to yield target strengths suitable for use with echo integrators. This has required compensation for both thresholding and saturation, since these operations can significantly bias data intended for use with systems, such as echo integrators, whose dynamic ranges are much larger. A nonparametric statistical method is introduced for this purpose. Pure-species acoustic data are extracted in several two-species cases by a method for separating superimposed frequency distributions. Mean in situ target strengths are presented for cod, saithe, Norway pout, herring, redfish, and greater silver smelt. For comparison with other data, these are expressed through the standard equation $\overline{\mathrm{TS}}=20 \log l+b$, where $\overline{\mathrm{TS}}$ is the mean target strength in decibels, and $l$ is the fish length in centimeters. For gadoids of lengths from 10 to over $105 \mathrm{~cm}, b=-67.5 \mathrm{~dB}$. For herring of lengths from 24 to 34 $\mathrm{cm}, b=-72.1 \mathrm{~dB}$. The often-ignored problem of obtaining unambiguous biological data by trawl sampling is discussed.

PACS numbers: 43.30.Dr, 43.20.Fn, 43.30.Sf, 43.80.Jz

\section{INTRODUCTION}

The need for knowledge of fish target strength is well known. ${ }^{1}$ In situ measurements are particularly valuable for representing the acoustic scattering properties of fish under the actual conditions of their surveying. Such data acquire a greater significance when used to determine the length dependence of target strength, as the resulting relation can then be used on fish of different lengths than originally observed and also, under certain circumstances, on fish of different species.

Development of the first commercial split-beam echo sounder, by SIMRAD, was therefore welcomed for its evident usefulness in determining in situ target strengths. By providing a means of direct measurement, the split-beam technique avoids many of the problems intrinsic to indirect methods. ${ }^{2}$ It is additionally superior in principle, if not in practice too, to the only other direct in situ method, that of dual beams, ${ }^{3}$ when the effect of noise is considered. ${ }^{4}$

Data derived with the split-beam echo sounder cannot be used immediately in ordinary echo surveying work, however, because of general differences in thresholds. The same is true of data derived with the dual-beam echo sounder. ${ }^{5}$ An additional problem associated with a limited dynamic range in direct-target-strength-measuring systems is the presence of a maximum-signal level. For the split-beam system, this resembles saturation, and each echo whose pressure exceeds the maximum registration level is recorded at this maximum level.

The two problems of thresholding and saturation are addressed here, with the aim of showing how the split-beam echo sounder can be used to determine target strengths for application in echo surveying. In the course of analyzing data from the first research cruises with the new instrument, the problem of separating two superimposed target strength distributions is also addressed, although for a prescribed but still important case. A very tangible result of this study is a set of mean in situ target strengths for six species of fish at 38 $\mathrm{kHz}$, for use in interpreting echo integrator data.

\section{MATERIALS}

The primary materials consist of the acoustic and biological data collected on a number of species during cruises on R/V G. O. SARS, a 75-m-long stern trawler, about Lofoten in March 1984 and the Shetland Islands in July 1984, cf. Fig. 1.

\section{A. Biological data}

The biological data, like the acoustic data, were collected from R/V G. O. SARS. The ensonified fish aggregations

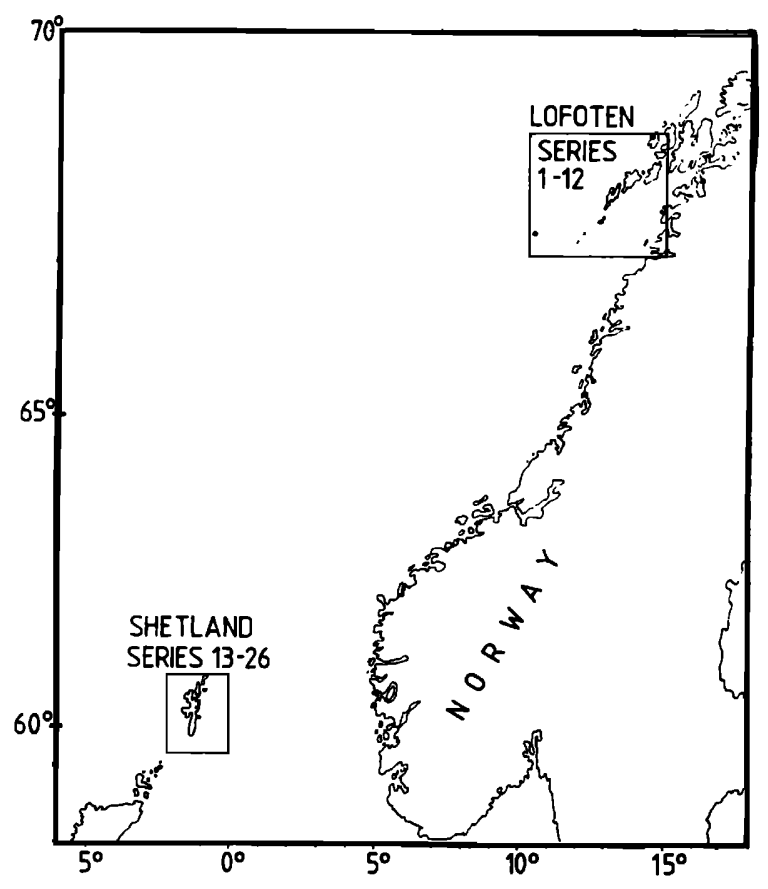

FIG. 1. Regions of data collection. 


\begin{tabular}{|c|c|c|c|c|c|c|c|c|c|c|c|c|}
\hline \multirow{3}{*}{$\begin{array}{l}\text { Data } \\
\text { series }\end{array}$} & \multirow{3}{*}{$\begin{array}{l}\text { Survey } \\
\text { date }\end{array}$} & \multirow[b]{3}{*}{ Fish } & \multirow{2}{*}{\multicolumn{2}{|c|}{ No. specimens }} & \multirow{2}{*}{\multicolumn{4}{|c|}{ Fish length $(\mathrm{cm})$}} & \multicolumn{4}{|c|}{$\begin{array}{l}\text { Assumed length distribution } \\
\text { in simulations }\end{array}$} \\
\hline & & & & & & & & & \multicolumn{2}{|c|}{$N($ mean, s.d. $)$} & \multicolumn{2}{|c|}{$\begin{array}{l}\text { Truncation } \\
\text { limits }\end{array}$} \\
\hline & & & Caught & Sized & Mean & s.d. & Min. & Max. & Mean & s.d. & Min. & Max. \\
\hline \multirow[b]{2}{*}{1} & \multirow[b]{2}{*}{$12 / 3$} & Norway pout & 223 & 223 & 17.6 & 1.6 & 10 & 21 & 17.6 & 1.6 & 14.4 & 20.8 \\
\hline & & Saithe & 52 & 52 & 59.7 & 4.9 & 48 & 69 & 57.2 & 6.0 & 45.2 & 69.2 \\
\hline \multirow{3}{*}{$\begin{array}{l}2 \\
3\end{array}$} & \multirow{3}{*}{$\begin{array}{l}13 / 3 \\
13 / 3\end{array}$} & Saithe & 1863 & 73 & 57.2 & 6.0 & 45 & 91 & 57.2 & 6.0 & 45.2 & 69.2 \\
\hline & & JRedfish & 92 & 92 & 19.7 & 8.7 & 9 & 43 & 19.7 & 8.7 & 11.0 & 37.1 \\
\hline & & Saithe & 15 & 15 & 56.3 & 5.1 & 46 & 65 & 57.2 & 6.0 & 45.2 & 69.2 \\
\hline 7 & $15 / 3$ & Cod & 13 & 13 & 81.7 & 10.6 & 60 & 98 & 81.6 & 11.4 & 58.8 & 104.4 \\
\hline 8 & $15 / 3$ & G. s. smelt & 1813 & 1813 & 37.2 & 4.4 & 25 & 50 & 37.2 & 4.4 & 28.4 & 46.0 \\
\hline 11 & $18 / 3$ & Cod & [Unspec. & 953 & 81.6 & 11.4 & 50 & $105+1$ & 81.6 & 11.4 & 58.8 & 104.4 \\
\hline 15 & $25 / 7$ & Herring & 165 & 165 & 28.8 & 2.0 & 24 & 34 & 28.5 & 2.0 & 24.5 & 32.5 \\
\hline 25 & $29 / 7$ & Herring & 22 & 22 & 28.0 & 2.7 & 25 & 34 & 28.5 & 2.0 & 24.5 & 32.5 \\
\hline 26 & $30 / 7$ & Norway pout & 2250 & 107 & 14.8 & 1.1 & 12 & 19 & 14.8 & 1.1 & 12.6 & 17.0 \\
\hline
\end{tabular}

were sampled by trawls immediately prior to, during, or immediately after the target strength collection runs. The type of trawl to be used, either bottom or pelagic, was chosen from the vertical distribution of the fish shown on the echo sounder paper record.

The bottom trawl was a shrimp trawl with 80-mm mesh size, circumference of 1800 meshes in front, and $20-\mathrm{mm}$ mesh size in the cod end. When towed at a speed of $3 \mathrm{kn}$, its horizontal and vertical openings are, respectively, 18 and 4 $\mathrm{m}$. The pelagic trawl was a herring trawl with a rectangular opening of $21 \times 10$ meshes of 6400 -mm mesh size in the front and $22-\mathrm{mm}$ mesh size in the cod end. When towed at $3-4 \mathrm{kn}$, its horizontal and vertical openings are approximately 35 and $20 \mathrm{~m}$, respectively.

Along the Lofoten Islands, spawning cod (Gadus mor$h u a$ ) of lengths generally exceeding $70 \mathrm{~cm}$ were observed in pure concentrations between 100- and 200-m depth. On the outer banks, immature saithe (Pollachius virens) of 50- to $65-\mathrm{cm}$ length were found in schools and scattering layers below $100-\mathrm{m}$ depth. In some cases, the recordings of saithe overlapped scattered concentrations of Norway pout (Trisopterus esmarki) and small redfish (Sebastes marinus) closer to the bottom. In the deeper parts of Vestfjord, the body of water between the Lofoten Islands and the mainland, at bottom depths of $250 \mathrm{~m}$ and more, scattering layers of greater silver smelt (Argentina silus) were observed. All species showed the usual diurnal behavior, forming small schools usually close to the bottom during the day, but ascending somewhat and dispersing at night, thus giving suitable conditions for single-fish target strength measurements.

About the Shetland Islands, suitable observing conditions were only obtained at night and generally only for the darkest hours. For the present observations, which were obtained in an area off the southeastern coast of Shetland, a mixture of plankton and 0-group gadoids consisting of Norway pout, haddock (Melanogrammus aeglefinus), and whiting (Merlangius merlangus) dominated the echo recordings in the upper $50 \mathrm{~m}$, while adult Norway pout were caught in quantities close to the bottom. Additionally, in parts of the area, dispersed herring (Clupea harengus) were recorded and caught in layers of depth $15-45 \mathrm{~m}$ and $65-95 \mathrm{~m}$.

The acoustic data are valuable only when accompanied by good biological data on rather pure fish aggregations. The species and length compositions in each trawl haul and the corresponding echo sounder paper record were therefore carefully examined. Only catches showing a clearly dominant single species or two species of distinct length groups which also could be recognized on the paper record were accepted for further use.

Thus, of the 11 data series from the March Lofoten cruise, only five, numbered 1, 2, 3, 7, and 8 in Table I, qualify unconditionally here for further analysis. Biological data for series 11 were taken from commercial Danish seine catches over the period 8-14 March in the same areas as the acoustic data were sampled. As this is the main area of commercial fishing for spawning cod, trawling was impossible. The authors are nonetheless confident that the species and length composition determined by Danish seining are representative for the recorded fish. The similarity of these data with those determined by trawling by R/V G. O. SARS in an area slightly further east on 15 March is also noted.

Of the 14 data series collected during the July Shetland Islands cruise, only three are sufficiently clean for analysis here. Data series 15 was collected on herring dispersed in the 65- to 95-m layer, while series 25 was collected on herring from the same layer immediately after rising to the 15- to 45$m$ layer. The herring catch was rather small, but the length distributions of the fish from the respective layers were essentially identical and also equivalent to those from daytime catches in the same area. The mean of the combined length data is $28.5 \mathrm{~cm}$; the standard deviation is $2.0 \mathrm{~cm}$. The catch from the upper layer also contained some 0-group gadoids of mean length $6.8 \mathrm{~cm}$ and standard deviation $1.6 \mathrm{~cm}$. Data series 26 represents adult Norway pout dispersed in a layer from the bottom to a height $15 \mathrm{~m}$ over the bottom. The trawl haul showed by numbers $96 \%$ Norway pout and $4 \%$ whiting of mean length $31.1 \mathrm{~cm}$ and standard deviation $4.7 \mathrm{~cm}$.

All measurements of fish length reported here refer to the so-called total length. ${ }^{6,7}$ For work performed at the Institute of Marine Research, this is essentially the distance from 
the anteriormost extremity, e.g., tip of the snout if protruding beyond the end of the lower jaw, to the end of the tail fin. In the case of fish with a forked tail, the two lobes are moved into the position which gives the maximum length measurement.

\section{B. Acoustic data}

\section{Split-beam echo sounder}

The acoustic data were gathered with the SIMRAD ES380 split-beam echo sounder, with hull-mounted transducer resonant at $38 \mathrm{kHz}^{8}$ In this device, essentially a $2 \times 2$ element phased array, each quadrant signal is separately amplified according to the same time-varied-gain function. The four quadrant beams are combined in pairwise fashion by simple summing to form a total of four half beams. The zero crossings of corresponding half-beam signals are detected and used to determine the alongships and athwartships phase differences, thence angles. Together, these two numbers specify the angular location of the detected scatterer, if present. The same numbers serve as an address for accessing a programmable-read-only memory (PROM) containing the measured beam pattern values.

Simultaneous with the operations on the half-beam signals, the port and starboard half-beam signals are summed to produce a total-signal output. Following envelope detection and analog-to-digital conversion, another PROM is accessed to determine the logarithm of the signal amplitude. This and the beam pattern compensation value form a set of addresses for a third PROM, which provides the target strength value, in coded form, for the particular time sample. A sequence of target strength values spanning the interval from the start of echo-signal reception to its termination by arrival of the bottom echo is derived for each individual transmission. For the fixed sampling frequency of 7.3625 $\mathrm{kHz}$ and design sound speed of $1472.5 \mathrm{~m} / \mathrm{s}$, the nominal depth resolution is $10 \mathrm{~cm}$.

The sequence of target strength values is reduced by software before the next transmission, which is governed by the pulse repetition frequency, nominally $50 / \mathrm{min}$ for the depths encountered during the measurements. The purpose of this data processing is the extraction of all single-fish echoes lying within the operator-specified depth interval.

To describe the criteria for extracting single-fish echoes, it is useful to introduce two quantities. The minimum detectable signal (MDS) is that corresponding to the least target strength of representation, $-50 \mathrm{~dB}$, when detected at the maximum allowable angle, $4.94 \mathrm{deg}$, where the two-way beam pattern loss is $-12 \mathrm{~dB}$. For angles greater than 4.94 deg, a zero code is generated. The duration of a single-fish echo is measured at the MDS level and is compared with the duration of the transmit signal as measured at the one-half power points of the detected envelope.

For the present application, a single-fish echo was defined as that set of contiguous nonzero-coded target strengths, whose duration lay within $75 \%$ and $175 \%$ of the transmit pulse duration and which was bordered by at least four zero-coded target strengths on either side. For the transmit pulse duration of $1 \mathrm{~ms}$, the minimum distance of separation between scatterers was thus greater than $1 \mathrm{~m}$.

Each single-fish echo is characterized by three data: the ping number, echo range to the nearest decimeter, and target strength, expressed as one of 80 target strength classes evenly spread over the range from -50 to $-20 \mathrm{~dB}$, hence with 0.375-dB resolution. The target strength is, in fact, an approximation, being the largest of the arithmetical means of target strengths computed for each pair of adjacent samples. Given the described resolution in target strength, this averaging is expected to incur only a slight negative bias, estimated to be less than $0.1 \mathrm{~dB}$ in magnitude, and neglected elsewhere in this paper.

\section{Calfbration}

The split-beam echo sounder was calibrated with a 60 mm copper sphere ${ }^{9,10}$ on axis in the exact manner of Ref. 11 at least once during each cruise. Direct measurement of the two-way beam pattern during a cruise in November 1985 revealed irregularities in beam shape consistent with the manufacturing specifications but requiring an overall adjustment of measured target strengths by $-0.4 \mathrm{~dB}$. This is moderated by the bias of $-0.1 \mathrm{~dB}$ introduced by a hardware operation in the echo sounder. Measurements of target strength thus had to be reduced by $0.3 \mathrm{~dB}$, which has been done in all computations reported here. In referring, in text and figures, to the measurements as made, however, the original target strength scale and class division are retained.

Detailed analysis of the errors due to measurement of the on-axis value and overall beam-pattern correction factor disclosed a calibration error due to procedure of $\pm 0.6 \mathrm{~dB}$ with $95 \%$ confidence. This may be compared with the figure derived by Simmonds $e t$ al. for a calibration performed under more controlled conditions, namely $\pm 0.2 \mathrm{~dB}$, which was also estimated to apply with $95 \%$ confidence. $^{12}$

The basic quantization level or step of the echo sounder is $0.375 \mathrm{~dB}$, implying an additional error of $\pm 0.2 \mathrm{~dB}$. The combined error due to calibration procedure and quantization is thus established to be $\pm 0.6 \mathrm{~dB}$ with $95 \%$ confidence.

\section{Fish target strength}

Acoustic data corresponding to the catch data in Table I are summarized through histograms of in situ target strength in Fig. 2. Additional data in the form of ping number and depth, which were attached to each respective target strength datum, are neglected here. Thus, according to Ref. 8 , some of the measurements included in the histograms derive from the same fish observed repeatedly during passage of the vessel and echo sounder beam. Such multiple observations, which may involve from about $15 \%$ to more than $50 \%$ of the total number of single-fish data, are not expected to bias the results, although reference to the original data and recomputation could decide the matter if necessary.

Some circumstances of the acoustic data collection are given in Table II. Both the depth range and ship speed refer to the analyzed data. The depth is actually the sum of the depth of the hull-mounted transducer, which is about $5 \mathrm{~m}$, 

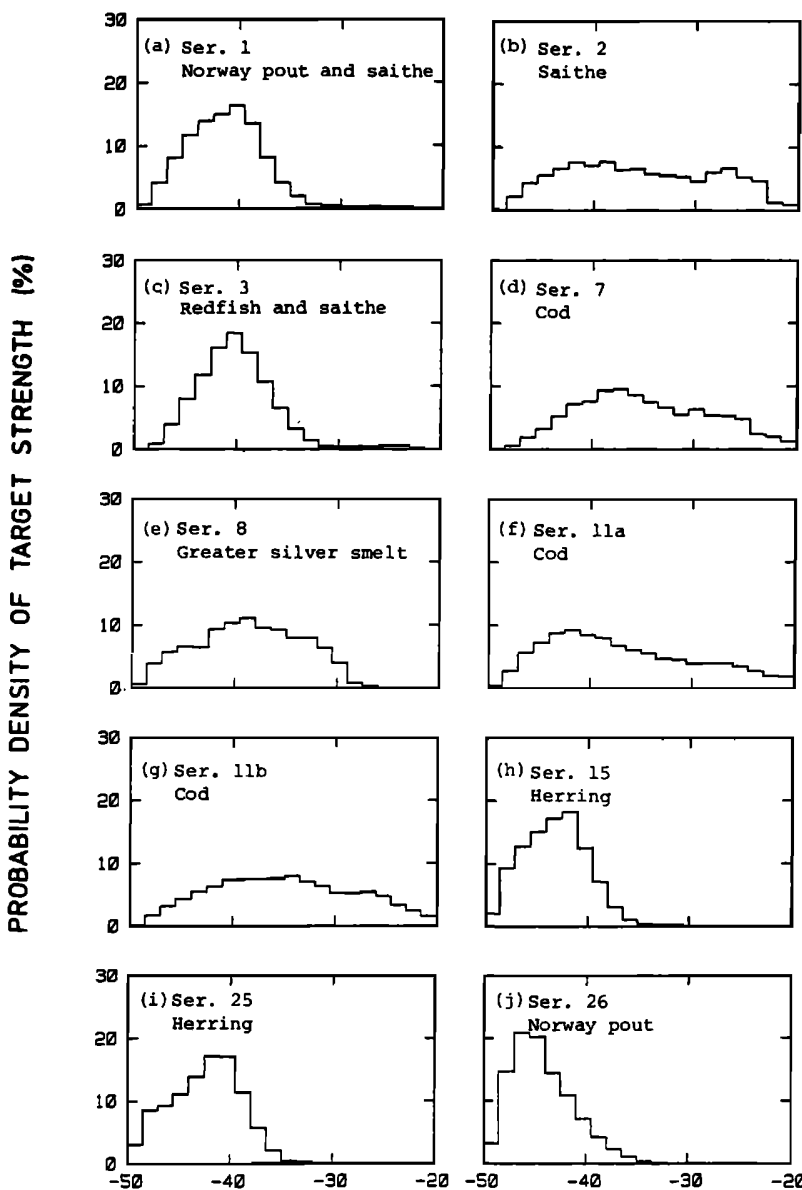

TARGET STRENGTH (DB)

FIG. 2. Target strength histograms of ten data sets derived with the splitbeam echo sounder. See Tables I and II for further details.

and the target range. However, since targets are accepted by the ES380 system only if lying within 4.94 deg of the acoustic axis, the depth estimate is only very slightly biased.

Generally, fewer data were analyzed than were available. One reason for this was the desire to maintain a homogeneous data set, as for example by limiting the vessel speed to a narrow range or by limiting the fish echoes to a narrower depth range than was actually employed during the observations.

\section{METHODS}

Two basic problems must be addressed in analyzing the data presented in Fig. 2.

\section{A. Separation of composite target strength histograms}

In the case of those data consisting of mixed species, namely those of series 1 and 3 , the target strength data in Fig. 2 (a) and (c) must be assigned to the individual fishes. The solution to this problem is referred to as the "method of separation."

It is apparent from Table I that the saithe length distributions of series 1 and 3 resemble those of series 2 . In fact, the geographical areas of the three series are essentially the same, being the fishing banks west of Lofoten. Thus the relative contribution of the saithe to the composite target strength histograms of Fig. 2(a) and (c) is known. Because the second species of the two data series, Norway pout and redfish, respectively, is smaller than the saithe, the greatest target strengths of the largest Norway pout and redfish will undoubtedly be substantially less than the greatest target strengths of the largest saithe. ${ }^{13}$

The difference in peak dorsal aspect target strengths of the several fishes can be estimated by reference to Nakken and Olsen's target strength data. ${ }^{13,14}$ The appropriate equations share the common form

$$
\mathrm{TS}_{\max }=m \log l+b,
$$

where $\mathrm{TS}_{\max }$ is the maximum dorsal aspect target strength in decibels, $l$ is the fish length in centimeters, and the coefficients $m$ and $b$ are determined by a least-mean-squares regression analysis. For saithe the result is

$$
\mathrm{TS}_{\max }=23.4 \log l-65.1 \text {, }
$$

or, requiring that $m=20$,

$$
\mathrm{TS}_{\max }=20 \log l-60.2 \text {. }
$$

If a nominal length of $70 \mathrm{~cm}$ is used for the largest saithe in each of data series 1 and 3, then the maximum dorsal aspect

\begin{tabular}{|c|c|c|c|c|c|c|c|c|c|c|c|}
\hline \multirow{2}{*}{$\begin{array}{l}\text { Data } \\
\text { series }\end{array}$} & \multicolumn{3}{|c|}{ Measuring time } & \multicolumn{2}{|c|}{ Starting position } & \multicolumn{2}{|c|}{$\begin{array}{l}\text { No. single-fish } \\
\text { data }\end{array}$} & \multicolumn{2}{|c|}{$\begin{array}{c}\text { Depth range } \\
(\mathrm{m})\end{array}$} & \multicolumn{2}{|c|}{$\begin{array}{c}\text { Boat speed } \\
(\mathbf{k n})\end{array}$} \\
\hline & Date & Hour & $(\min )$ & Lat. $\left({ }^{\circ} \mathbf{N}\right)$ & Long. $\left({ }^{\circ}\right)$ & Total & Analyzed & Min. & Max. & Mean & s.d. \\
\hline 1 & $12 / 3$ & 2103 & 81 & 68.73 & $12.86 \mathrm{E}$ & 10400 & 9179 & 105 & 240 & 3.9 & 2.6 \\
\hline 2 & $13 / 3$ & 0031 & 23 & 68.54 & $12.43 \mathrm{E}$ & 3400 & 3000 & 105 & 130 & 2.9 & 0.2 \\
\hline 3 & $13 / 3$ & 1837 & 78 & 67.43 & $10.30 \mathrm{E}$ & 8600 & 7584 & 165 & 225 & 4.4 & 3.0 \\
\hline 7 & $15 / 3$ & 1912 & 48 & 68.11 & $14.58 \mathrm{E}$ & 5400 & 4400 & 70 & 165 & 2.7 & 0.2 \\
\hline 8 & $15 / 3$ & 2217 & 47 & 67.97 & $14.60 \mathrm{E}$ & 7800 & 2600 & 265 & 360 & 2.4 & 0.1 \\
\hline $11 \mathrm{a}$ & $18 / 3$ & 1736 & 87 & 68.10 & $14.52 \mathrm{E}$ & 9600 & 9600 & 85 & 160 & 11.3 & 0.4 \\
\hline $11 \mathrm{~b}$ & $18 / 3$ & 2155 & 65 & 68.10 & $14.46 \mathrm{E}$ & 9000 & 9000 & 85 & 160 & 3.3 & 0.3 \\
\hline 15 & $26 / 7$ & 0021 & 104 & 59.96 & $1.14 \mathrm{~W}$ & 10600 & 6545 & 65 & 95 & 7.1 & 2.9 \\
\hline 25 & $29 / 7$ & 2353 & 99 & 60.24 & $0.70 \mathrm{~W}$ & 5800 & 2687 & 15 & 45 & 5.5 & 3.8 \\
\hline 26 & $30 / 7$ & 2248 & 104 & 60.61 & $0.63 \mathrm{~W}$ & 24000 & 4201 & 85 & 115 & 4.2 & 3.7 \\
\hline
\end{tabular}
target strength is expected to be about -23 or $-22 \mathrm{~dB}$.

TABLE II. Conditions of acoustic data collection. 
This agrees well with the observations in Fig. 2(a) and (c), if requiring some squinting to confirm.

Maximum dorsal aspect target strengths of Norway pout and redfish are not reported in the literature. Norway pout is a gadoid, hence for present purposes might be represented as having a target strength roughly comparable to that of other gadoids of similar length. For want of a closer kinship, the maximum target strength relation for Norway pout is based on the combined cod, saithe, and pollack (Pollachius pollachius) data of Nakken and Olsen. It is

$$
\mathrm{TS}_{\max }=24.5 \log l-67.1 \text {, }
$$

or, requiring that $m=20$,

$$
\mathrm{TS}_{\max }=20 \log l-60.5 \text {. }
$$

Thus, for the largest observed Norway pout, with $l=21 \mathrm{~cm}$, the maximum target strength is expected to be about -35 or $-34 \mathrm{~dB}$.

Redfish is not a gadoid. If gadoid data are appropriate, however, a maximum target strength of about -28 or $-27 \mathrm{~dB}$ could be expected from the largest caught specimen of $43 \mathrm{~cm}$. However, comparison of the target strength histograms of Fig. 2(b) and (c) suggests a possible greatest redfish target strength of $-30.5 \mathrm{~dB}$.

Separation of the saithe contribution from the composite histograms in Fig. 2(a) and (c) is accomplished by attributing all data above the likely greatest target strength of the second, lesser fishes to saithe. The number of represented saithe data above this cutoff represents the same fraction of the entire saithe distribution as does the comparable part of the pure-saithe target strength histogram in Fig. 2(b). The pure-saithe histogram can thus be scaled absolutely, and the part below the cutoffs in Fig. 2(a) and (c) can be subtracted directly from the composite histogram. The result of applying this procedure to the composite data in Fig. 2(a) and (c) is shown in Fig. 3(a) and (b), respectively.

\section{B. Threshold and saturation compensation}

\section{Background}

The problem of extracting the mean target strength is common to all data sets. This would be trivial, indeed, if the intended application involved the same threshold and saturation effects. However, since echo integrators generally register both weaker and stronger signals than the split-beam echo sounder does, the matter cannot be ignored.

Consideration of the range in fish sizes and likely corresponding target strengths ${ }^{13,14}$ suggests that the target strengths of the largest cod have not been correctly represented because of saturation at $-20 \mathrm{~dB}$. Similarly, the target strengths of fish shorter than $30 \mathrm{~cm}$ often lie well below the lower threshold of $-50 \mathrm{~dB}$. Thus there is particular justification for investigating the effects of thresholding and saturation on the underlying target strength data of this study.

Weimer and Ehrenberg have approached the problem of thresholding by means of parametric statistics. ${ }^{5}$ Under the assumptions of a normal distribution in target strength and equally likely probability of occurrence in the echo sounder
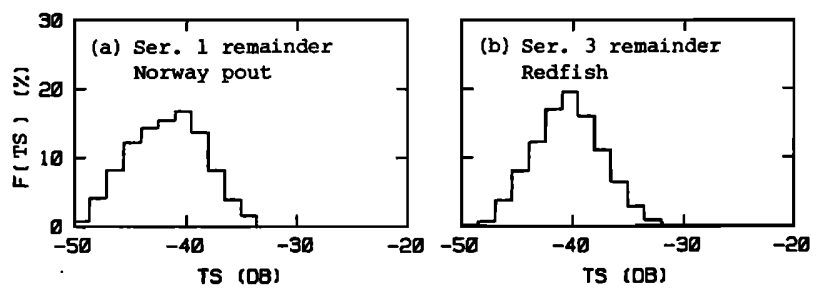

FIG. 3. Target strength histograms derived from Fig. 2(a) and (c) by removal of the saithe contributions.

beam, they derived an exact expression for the threshold effect. The effect of saturation could be incorporated in this, although less simply than by a mere change in the upper limit of integration. In addition, the assumed normal distribution could be replaced by the actual observed distribution, ${ }^{15}$ although generally incomplete because of the several delimiting operations.

The empirical data of this study, shown in Figs. 2 and 3, appear for the most part to be non-normally distributed. This should not be surprising, perhaps, for Clay and Heist have found the echo amplitude to be distributed according to Ricean statistics, ${ }^{16}$ and other recent modeling work based on representing a fish by its swimbladder and assuming the usual normal tilt-angle distribution has confirmed the non-normal nature of target strength. ${ }^{17}$ Extrapolation of the target strength distributions by application of the methods in Refs. 16 and 17 was not attempted for want of sufficient behavioral and morphometric data. Thus a different approach has been pursued here.

\section{Plan}

The effect of thresholding and saturation by the splitbeam echo sounder at -50 and $-20 \mathrm{~dB}$ is estimated by comparing the pure-species target strength histograms of Figs. 2(b), (d)-(j), and 3 with target strength histograms simulated for comparable species from Nakken and Olsen's data. ${ }^{13}$ Computation of the simulated target strength histograms, or theoretical distributions, is reviewed in the next section.

In essence, an observed target strength histogram, or empirical distribution, is first trimmed at one or both ends to avoid the biasing influence of target strengths over $-50 \mathrm{~dB}$ or under $-20 \mathrm{~dB}$, affected, respectively, by thresholding or saturation. The trimmed empirical distribution is then extended by appending the tails of the theoretical distributions. Proper allowance must be made for the relative proportions of truncated and added endpieces of the distributions. This is discussed in Sec. II B 4.

Additional compensation of the final, averaged target strengths for the threshold and saturation levels of the intended devices of application, modern echo-integrating systems, is unnecessary. The reason, simply, is that these levels lie far beyond the ordinary range of single-fish target strengths.

\section{Simulating target strength histograms}

The target strength simulation data were derived directly from Nakken and Olsen's data. ${ }^{13}$ To form a uniform basis 
having the same length distribution as that observed, only those target strength functions were used whose corresponding fish lengths lay within the truncation limits shown in Table I. The measured target strength functions were then scaled in both angle and magnitude to simulate the functions of a series of fish spanning the length range. Simulation of the target strength function $\operatorname{TS}^{\prime}\left(\theta^{\prime}\right)$ of tilt angle $\theta^{\prime}$ for a fish of length $l^{\prime}$ from the measured function $\operatorname{TS}(\theta)$ for a fish of length $l$ was accomplished by the transformation:

$$
\begin{aligned}
& l \rightarrow l^{\prime}, \\
& \theta-\theta_{\max } \rightarrow\left(l^{\prime} / l\right)\left(\theta^{\prime}-\theta_{\max }\right), \\
& \text { TS } \rightarrow \text { TS }-20 \log \left(l^{\prime} / l\right) .
\end{aligned}
$$

The angle of maximum target strength, denoted by $\theta_{\max }$, is assumed to be unchanged under the transformation. Target strength values lost in cases of contraction of the original function were replaced by values derived from the very approximate relation $\mathrm{TS}_{\min }=30 \log l^{\prime}-100$, where $l^{\prime}$ is expressed in centimeters. This was established by cursory inspection of the data in Ref. 14.

For each of these simulated functions, a target strength histogram was computed in an analogous manner to that of Ref. 17. These theoretical histograms were subsequently compounded according to a truncated normal distribution of fish length having the characteristics given in Table $I$.

Representation of the several fishes in the simulation was one-to-one for cod, saithe, and herring. For both Norway pout and the non-gadoid but physoclistous redfish and greater silver smelt, Nakken and Olsen's ${ }^{13}$ combined data for cod, saithe, and pollack were used.

In order to compute a target strength histogram from simulated data, a specific behavior mode has to be assumed. Because of the present use of a vertical echo-sounding system, this is described adequately by the distribution of tilt angle. ${ }^{18,19}$ Notwithstanding broad recognition of its importance, and recent development of a transponding tilt-anglemeasuring tag by R. B. Mitson at the Fisheries Laboratory in Lowestoft, England, tilt angle distributions have been determined at sea for only three species. ${ }^{20-22}$ Given the sensitivity of the tilt angle distribution to behavior, for example, directed horizontal swimming contra feeding contra diving, this is clearly unknown for the observed fish.

The state of nearly total ignorance of fish behavior was remedied by assuming a range of behavioral modes, performing the described computations for each, and averaging the results over the entire set. A single assumption was made about the behavior: that it was not extreme. This hypothesis was theoretically sustained, in fact, for simulated target strength distributions with mean tilt angles greater than 10 deg from the horizontal generally lack or under-represent the largest observed target strengths. Therefore, if the target strength measurements of Nakken and Olsen ${ }^{13}$ and their applicability ${ }^{23}$ can be believed, then strong avoidance reactions with diving ${ }^{24,25}$ are simply incompatible with the observations. The nonextreme behavior modes were characterized by normal distributions in tilt angle with means of $-10,-5,0,5$, and 10 deg and standard deviations of 5,10 , and $15 \mathrm{deg}$.

In simulating the target strength histograms with respect to normal distributions of tilt angle, the effect of per- spective ${ }^{19}$ was incorporated by increasing the first two standard deviations to 5.5 and $10.2 \mathrm{deg}$, while leaving the third unchanged. These values were determined for an ideal circular beam pattern with sharp edge $5 \mathrm{deg}$ from the acoustic axis, assuming an equally likely probability of occurrence anywhere in the horizontal plane.

\section{Mean target strengths}

All averaging was accomplished in the intensity domain, hence with respect to the backscattering cross section $\sigma$. The relation between target strength TS and $\sigma$ assumed throughout this paper is that given by the traditional and usual definition,

$$
\mathrm{TS}=10 \log (\sigma / 4 \pi),
$$

as in Urick, ${ }^{26}$ but with SI units. The mean target strength $\overline{\text { TS }}$ for a particular behavior mode is defined in terms of the average backscattering cross section $\bar{\sigma}$ by analogy,

$$
\overline{\mathrm{TS}}=10 \log (\bar{\sigma} / 4 \pi) \text {. }
$$

For the special case of a uniform target strength distribution over the interval from $\mathrm{TS}_{1}$ to $\mathrm{TS}_{2}$, the mean backscattering cross section $\sigma$ is

$$
\bar{\sigma}=\frac{40 \pi}{\ln 10} \frac{10^{\mathrm{TS}_{2} / 10}-10^{\mathrm{TS}_{1} / 10}}{\mathrm{TS}_{2}-\mathrm{TS}_{1}}
$$

This is, in fact, the prescription used in assigning mean backscattering cross sections to the various target strength classes of the several distributions. The basic target strength interval, $\mathrm{TS}_{2}-\mathrm{TS}_{1}$, used in the computations was $1.5 \mathrm{~dB}$.

Compensation for thresholding and saturation is applied in the determination of $\bar{\sigma}$, which begins with the straightforward averaging of the observed target strength histogram, or empirical distribution, with result $\bar{\sigma}_{e}$. The two compensations are now described.

a. Lower tail. This compensation involves extrapolating the observed target strength distribution below the nominal threshold of $-50 \mathrm{~dB}$. As the effect of the threshold is sharp only for scatterers with target strengths greater than about $-47 \mathrm{~dB}$, and since scatterers with target strengths between -50 and $-47 \mathrm{~dB}$ are unequally registered by the echo sounder, the effective threshold may exceed $-50 \mathrm{~dB}$. This quantity, referred to as the lower cutoff, was chosen to optimize the agreement of empirical and theoretical distributions at their junction. Six discrete levels were examined, from -50 to $-42.5 \mathrm{~dB}$ in steps of $1.5 \mathrm{~dB}$. In practice, the cutoff was determined from among the three lowest levels, the higher ones always giving a much poorer agreement.

The contributions of the lower tails of the empirical and theoretical distributions to their respective averages were computed for target strengths not exceeding the chosen cutoff. These are denoted $\Delta \sigma_{e, a}$ and $\Delta \sigma_{t, a}$, respectively. The proportions of the histograms, or distributions, represented by the several contributions, $p_{e, a}$ and $p_{t, a}$, were also computed.

Compensation for the threshold is effected by loping off the lower tail of the empirical distribution and appending the lower tail of the theoretical distribution. When allowance is made for the change in the number of basis data, 


$$
\bar{\sigma}_{e} \rightarrow \frac{1-p_{t, a}}{1-p_{e, a}}\left(\bar{\sigma}_{e}-\Delta \sigma_{e, a}\right)+\Delta \sigma_{t, a}
$$

describes the effect on the uncompensated mean backscattering cross section $\bar{\sigma}_{e}$.

b. Upper tail. In compensating for saturation, the empirical distribution is terminated at $-21.5 \mathrm{~dB}$, which reduces $\bar{\sigma}_{e}$ by the amount $\Delta \sigma_{e, b}$. The corresponding proportion of the histogram is $p_{e, b}$. This is to be replaced by the upper tail of the theoretical distribution, lying above -21.5 $\mathrm{dB}$, with contribution $\Delta \sigma_{t, b}$ to the theoretical mean. The effective contribution is determined by scaling $\Delta \sigma_{t, b}$ in proportion to $p_{e, b}$ since, in saturation, no data are lost, but only wrongly classified in the highest target strength class. If the proportion of the theoretical distribution above $-21.5 \mathrm{~dB}$ is denoted $p_{t, b}$, then

$$
\bar{\sigma}_{e} \rightarrow \bar{\sigma}_{e}-\Delta \sigma_{e, b}+\left(p_{e, b} / p_{t, b}\right) \Delta \sigma_{t, b}
$$

describes the transformation of $\bar{\sigma}_{e}$ due solely to saturation.

c. Combined effect. The result of applying the two transformations is the fully compensated value

$\bar{\sigma}_{e}^{\prime}=\frac{1-p_{t, a}}{1-p_{e, a}}\left(\bar{\sigma}_{e}-\Delta \sigma_{e, a}-\Delta \sigma_{e, b}+\frac{p_{e, b}}{p_{t, b}} \Delta \sigma_{t, b}\right)+\Delta \sigma_{t, a}$.

This quantity was computed for each of the 15 investigated, nonextreme behavior modes. The ensemble average $\sigma^{*}$ was then computed as a simple arithmetic mean, and the sample variation due to ignorance of the behavior mode was estimated by computing the standard deviation $\Delta \sigma *$ in $\sigma^{*}$. Corresponding target strengths were determined analogously to Eq. (4), hence

$$
\mathrm{TS}^{*}=10 \log \left(\sigma^{*} / 4 \pi\right)
$$

and

$$
\mathrm{TS}_{ \pm}^{*}=10 \log \left[\left(\sigma^{*} \pm \Delta \sigma^{*}\right) / 4 \pi\right] .
$$

\section{RESULTS}

Threshold- and saturation-compensated mean in situ target strengths derived with the new split-beam echo sounder are shown in Table III. The uncertainty in target strength includes three effects: (1) error in calibration procedure, (2) quantization error, and (3) uncertainty over the exact behavorial mode or tilt angle distribution assumed in the course of complementing the original, generally truncat- ed, data series. The combined error due to the first two sources was established above to be $\pm 0.6 \mathrm{~dB}$ with $95 \%$ confidence. The error due to the third source was determined as the arithmetic mean of $\left(\mathrm{TS}_{+}^{*}-\mathrm{TS}^{*}\right)$ and (TS* - TS* ). The number shown in the table as an uncertainty in mean target strength is derived by combining the standard deviations of each of the three sources through the root-mean-square operation.

For comparison purposes, the quantity

$$
b_{20}^{*}=\text { TS }^{*}-20 \log \bar{l},
$$

where $\bar{l}$ is the mean fish length, is included in Table III. Its error is composed of the uncertainties in both target strength estimate TS* and mean length $\bar{l}$. As this last error depends on the representability of biological sampling by trawling, which remains unknown, no confidence limits are given.

The mean target strength derived by equal weighting of the three cod data is $-30.6 \mathrm{~dB}$. If this is used together with the tabulated data for the other gadoids, then the result of regressing the mean target strength on the logarithm of mean fish length is

$$
\mathrm{TS}_{\text {gadoids }}=20.2 \log l-67.8,
$$

which obtains with a standard error of $1.7 \mathrm{~dB}$. If the length dependence is constrained to be $20 \log \bar{l}$, then

$$
\overline{\mathrm{TS}}_{\text {gadoids }}=20 \log \bar{l}-67.5,
$$

with the same standard error. If each of the six tabulated gadoid data is weighted equally, then the resulting equations are $\overline{\mathrm{TS}}=18.9 \log \bar{l}-66.2$ and $\overline{\mathrm{TS}}=20 \log \bar{l}-68.0$, which obtain with respective standard errors of 1.4 and 1.5 dB.

If the matter of the depth dependence of the herring data is ignored, and the two target strengths are accorded equal weight, then the average target strength of a $28.5-\mathrm{cm}$ herring is $-43.0 \mathrm{~dB}$. If this single datum is allowed to determine the coefficient $b$ in the equation $\overline{\mathrm{TS}}=20 \log \bar{l}+b$, then

$$
\overline{\mathbf{T S}}_{\text {herring }}=20 \log \bar{l}-72.1 \text {. }
$$

\begin{tabular}{|c|c|c|c|c|c|c|c|}
\hline Fish & Length $(\mathrm{cm})$ & Depth (m) & $\begin{array}{l}\text { Boat speed } \\
\text { (kn) }\end{array}$ & No. data & $\begin{array}{l}\text { Target strength } \\
\text { (dB) }\end{array}$ & $\begin{array}{l}b_{20}^{*} \\
(\mathrm{~dB})\end{array}$ & $\begin{array}{l}\text { Data } \\
\text { series }\end{array}$ \\
\hline Cod & $81.6 \pm 11.4$ & $70-165$ & $2.7 \pm 0.2$ & 4400 & $-30.6 \pm 0.3$ & -68.9 & 7 \\
\hline Cod & $81.6 \pm 11.4$ & $85-160$ & $11.3 \pm 0.4$ & 9600 & $-31.0 \pm 0.3$ & -69.2 & $11 \mathbf{a}$ \\
\hline Cod & $81.6 \pm 11.4$ & $85-160$ & $3.3 \pm 0.3$ & 9000 & $-30.3 \pm 0.3$ & -68.5 & $11 b$ \\
\hline Saithe & $57.2 \pm 6.0$ & $105-130$ & $2.9 \pm 0.2$ & 3000 & $-30.6 \pm 0.3$ & -65.8 & 2 \\
\hline Norway pout & $17.6 \pm 1.6$ & $105-240$ & $3.9 \pm 2.6$ & 9179 & $-42.2 \pm 0.9$ & -67.1 & 1 \\
\hline Norway pout & $14.8 \pm 1.1$ & $85-115$ & $4.2 \pm 3.7$ & 4201 & $-44.9 \pm 0.9$ & -68.3 & 26 \\
\hline Redfish & $19.7 \pm 8.7$ & $165-225$ & $4.4 \pm 3.0$ & 7584 & $-40.6 \pm 0.5$ & -67.1 & 3 \\
\hline G. s. smelt & $37.2 \pm 4.4$ & $265-360$ & $2.4 \pm 0.1$ & 2600 & $-36.6 \pm 0.4$ & -68.0 & 8 \\
\hline Herring & $28.5 \pm 2.0$ & $65-95$ & $7.1 \pm 2.9$ & 6545 & $-43.4 \pm 0.5$ & -72.5 & 15 \\
\hline Herring & $28.5 \pm 2.0$ & $15-45$ & $5.5 \pm 3.8$ & 2687 & $-42.6 \pm 0.5$ & -71.7 & 25 \\
\hline
\end{tabular}

\section{DISCUSSION}

\section{A. Biological sampling}

The usefulness of in situ target strength measurements depends largely on the reliability of the accompanying biological data. In general, trawls are highly selective gears be-

TABLE III. Threshold-compensated mean in situ target strengths derived with the SIMRAD ES380 split-beam echo sounder. 
cause of mesh selection and because of both species and length dependent herding by all components of the trawl system, including vessel, warps, otterboards, bridles, and net. ${ }^{27}$ Hence, both species and length compositions in trawl hauls from areas where various species and size groups are mixed together are biased. Accordingly, also, the mean lengths calculated for such distributions are biased.

Hylen et $a l .^{28}$ have shown that the bottom trawl used in the present experiments largely undersamples small cod. Their studies also indicate that the number of captured fish of 10- to $15-\mathrm{cm}$ length must be multiplied by a factor of 8-10 in order to be comparable with the catch of $40-$ to $50-\mathrm{cm}$ fish. A similar trend has been observed for haddock. With regard to the pelagic trawl, Hylen et al. ${ }^{28}$ have shown that the largest cod are undersampled because these beasts are able to avoid the gear by diving beneath it during towing.

While these observations may give some general guidelines on the biases introduced by the sampling gear, the information is not sufficient for estimating the biases incurred for various species and length compositions, hence correction for such biases. Therefore, to ensure the quality of the biological data, only data from quite pure fish aggregations have been used. Additionally, it was required that the coefficient of variation of fish lengths in the respective catches be as low as possible. This was the case for all of the reported species except that of redfish, which has been included because of the rarity, if not uniqueness, of unambiguous acoustic observations on it.

\section{B. Acoustic data analysis}

Compensation for the threshold and saturation effects has been achieved through a combined comparison and extrapolation procedure based on simulated target strength distributions. These depend on the validity of the basis target strength data, presumed established, ${ }^{23}$ and knowledge of the fish behavior as expressed through the tilt angle distribution. Given nearly complete ignorance of the particular behavior patterns, a range of nonextreme behavior modes has been assumed. Averaging of the respective mean target strengths has revealed a rather low variance, with maximum standard deviation due only to uncertainty in behavior mode of 0.9 dB. Given the standard deviation due to other causes of 0.3 $\mathrm{dB}$, the standard deviation in estimated mean due to all error sources is therefore less than $1.0 \mathrm{~dB}$ in all cases, as shown in Table III. This is fortunate for indicating a basic insensitivity of threshold- and saturation-compensated in situ target strengths to the particular behavior mode, which is both unknown and difficult to know.

There is, however, clear support for the exclusion of extreme behavior patterns from the analysis of each data series here: It is the presence of relatively large target strengths in the distributions. If the mean tilt angle were, for instance, to deviate from the horizontal by more than about $10 \mathrm{deg}$, then it would be difficult, if not impossible, to explain the large target strengths that were observed. In a word; the present analysis indicates that fish detected within the acoustic beam were not seriously affected by the passage of the vessel. It is noteworthy in the same context that most of the data were collected at moderate speeds. In the case of
TABLE IV. Adjustments to the uncompensated mean target strengths according to two methods: the present nonparametric method and Weimer and Ehrenberg's method ${ }^{5}$ based on assumption of normality in target strength data. NC denotes not computed.

\begin{tabular}{lccc}
\hline \hline & & \multicolumn{2}{c}{ Adjustment to target strength } \\
\cline { 3 - 4 } Fish & Length (cm) & $\begin{array}{c}\text { Nonparametric } \\
\text { method }\end{array}$ & $\begin{array}{c}\text { Parametric } \\
\text { method }\end{array}$ \\
\hline Cod & $81.6 \pm 11.4$ & 0.2 & NC \\
Cod & $81.6 \pm 11.4$ & 0.2 & NC \\
Cod & $81.6 \pm 11.4$ & 0.1 & NC \\
Saithe & $57.2 \pm 6.0$ & 0.0 & -1.5 \\
Norway pout & $17.6 \pm 1.6$ & -1.5 & -1.1 \\
Norway pout & $14.8 \pm 1.1$ & -1.7 & -1.4 \\
Redfish & $19.7 \pm 8.7$ & -1.0 & -0.8 \\
G. s. smelt & $37.2 \pm 4.4$ & -0.6 & -1.3 \\
Herring & $28.5 \pm 2.0$ & -1.2 & -1.2 \\
Herring & $28.5 \pm 2.0$ & -1.2 & -1.2 \\
\hline \hline
\end{tabular}

cod, however, data were collected at each of several distinct speeds, varying from less than 3 knots to more than 11 knots, yet neither systematic nor significant differences in target strength were found.

Justification for the threshold and saturation compensation is provided by a comparison of the compensated mean target strengths with the corresponding mean target strengths as computed directly from the uncompensated split-beam data. The result is shown in Table IV under the heading "nonparametric method." Only in the case of saithe are the estimates identical, which indicates that the principal part of the target strength distribution for saithe is expected to lie within the acceptance range of the echo sounder. For the other fishes, the effect of compensation, as based solely on the mean values, varies from -1.7 to $0.2 \mathrm{~dB}$.

Included in Table IV are compensation factors derived from Weimer and Ehrenberg's parametric approach. ${ }^{5}$ In performing the computations, the true mean values were assumed to be those given in Table III, and the standard deviations were assumed equal to those characterizing the distributions in Figs. 2(b), (d)-(j), and 3. The value used for the factor $c$ in Eq. (30) of Ref. 5 is 0.895 , as given in Ref. 29, since the present 3-dB beamwidth is less than the specified 20 deg. Except for the case of cod, which was not computed, and that of saithe, which was, the agreement of corresponding nonparametric and parametric results is quite good.

While preparing the split-beam data for averaging, two instances of mixed-species data were encountered. In each of these, the distribution form of the component with the larger target strengths, namely saithe, was well known. This allowed subtraction of the entire large-fish contribution, leaving the small-fish distribution as the remainder for further analysis.

A degree of justification for this procedure lies in the final results: The target strengths of the Norway pout of 17.6-cm mean length and the redfish are in line with other physoclist in situ target strengths, both as determined in this study and as determined elsewhere. Exemplary, independently derived target strength data are provided by a series of measurements of walleye pollock (Theragra chalcogramma) with the dual-beam echo sounder..$^{2,15,29-31}$ 


\section{Comparisons}

The similarity of target strengths of cod and saithe, with respective mean lengths of 82 and $57 \mathrm{~cm}$, deserves particular comment, for according to Eqs. (9a) and (9b) the difference in length suggests a difference in target strength of more than $2 \mathrm{~dB}$, yet none is found.

Two general causes of this discrepancy are discussed. (1) Behavior. Avoidance reaction is believed unlikely because of the depth of saithe, in excess of $100 \mathrm{~m}$, and the demonstrably ship-speed-independent mean target strength of the shallower cod. Differences in less-extreme behavior modes, as related, for example, to ambient light intensity, feeding conditions, or migratory phase, may explain only part of the discrepancy when account is taken of possible species-based differences in target strength. ${ }^{19}$ (2) Swimbladder state. A difference in relative degrees of swimbladder inflation, due solely to depth, is also believed unlikely because of the similar physoclistous nature of the two gadoids, which are expected to maintain inflated swimbladders to remain neutrally buoyant. However, differences in the biological states of the two fishes, as due, for example, to the presence of spawning products, extent of stomach filling, or level of lipids, may explain considerable variations in both form and size of the swimbladder. ${ }^{32,33}$ These synoptic variations may account for the discrepancy, although detailed scattering computations in the manner of Ref. 17 have not been performed for want of suitable data.

Systematic comparison of the present results with other in situ data is foregone for the sake of brevity. Instead, several rather recent measurement results are quoted.

\section{Gadold target strength}

The relation derived on the sole basis of 13 pollack swimbladders and 2 saithe swimbladders, and assumption of cod behavior as described by Olsen, ${ }^{20}$ is ${ }^{17}$

$$
\overline{\mathbf{T S}}_{\mathrm{gadoids}}=20 \log \bar{l}-66.9 \text {, }
$$

which is to be compared with Eq. (9b).

\section{Herring target strength}

The relation recommended by the 1983 Planning Group on ICES-coordinated Herring and Sprat Acoustic Surveys, albeit anonymously, is ${ }^{34}$

$$
\mathrm{TS}_{\text {herring }}=20 \log \bar{l}-71.2 \text {, }
$$

which is to be compared with Eq. (10). Degnbol, Lassen, and Stæhr have, through an indirect in situ measurement method, determined the constant in this equation to be $-72.6 \mathrm{~dB}$ for herring in the Kattegat-Skagerrak ${ }^{35}$ and $-{ }^{7} 0.8 \mathrm{~dB}$ for herring in the Baltic Sea. ${ }^{36}$ For herring in the North Sea, Forbes has recently completed a preliminary study with the dual-beam system which indicates a value of $-73.6 \mathrm{~dB} \cdot{ }^{37}$ Forbes regards this result as being quite tentative because of the problem of species identification in the surveyed, mixed-species environment.

The variance in the several numbers reported here may be due to measurement error, of course, but may also reflect, in the words of Traynor, ${ }^{31}$ the dynamic nature of fish target strength.

\section{Future work and afterword}

Much more remains to be done with the data analyzed here. Three examples of future studies are the following: (1) determination of the depth dependence of the herring target strength, (2) compensation for thresholding and saturation on the basis of data simulated from swimbladder morphometries, and (3) investigation of avoidance reactions through a statistical analysis of echo trace lengths. ${ }^{1,38}$ Another study which could be profitably undertaken, were better behavioral data forthcoming, is a refinement of the present target strength values based on more certain specification of the applicable tilt angle distributions.

It is interesting retrospective of the introduction of the split-beam echo sounder one year $\mathbf{a g o}^{8}$ to note that the potential of the instrument is being realized. However, it is also exceedingly important to call the attention of current and future users of the equipment to the hazards of ignoring thresholding and saturation, the Scylla of $-50 \mathrm{~dB}$, the Charybdis of $-20 \mathrm{~dB}$.

\section{ACKNOWLEDGMENT}

A. Raknes is thanked for collecting the acoustic data on cod on 18 March 1984. This paper is an expanded version of a report presented at the Statutory Meeting of the International Council for the Exploration of the Sea, held in London, 7-16 October 1985.

${ }^{1}$ L. Midttun, "Fish and other organisms as acoustic targets," Rapp. P. -v. Réun Cons. Int. Explor. Mer. 184, 25-33 (1984).

${ }^{2} J$. E. Ehrenberg, "A review of in situ target strength estimation techniques," FAO Fish. Rep. (300), 85-90 (1983).

${ }^{3}$ J. E. Ehrenberg, "Two applications for a dual beam transducer in hydroacoustic fish assessment systems," Proc. 1974 IEEE Conf. Eng. Ocean Environ. 1, 152-155 (1974).

4J. E. Ehrenberg, "A comparative analysis of in situ methods for directly measuring the acoustic target strength of individual fish," IEEE J. Ocean. Eng. OE-4(4), 141-152 (1979).

${ }^{5}$ R. T. Weimer and J. E. Ehrenberg, "Analysis of threshold-induced bias inherent in acoustic scattering cross-section estimates of individual fish," J. Fish. Res. Board Can. 32, 2547-2551 (1975).

${ }^{6}$ T. Laevastu, "Manual of methods in fisheries biology," FAO Man. Fish. Sci. (1) (1965).

${ }^{7}$ K. F. Lagler, "Capture, sampling and examination of fishes," in Methods for the Assessment of Fish Production in Fresh Waters, edited by T. Bagenal (Blackwell, Oxford, England, 1978), 3rd ed., Chap. 2, pp. 7-47.

${ }^{8}$ K. G. Foote, F. H. Kristensen, and H. Solli, "Trial of a new, split-beam echo sounder," Coun. Meet. Int. Coun. Explor. Sea 1984/B:21, Copenhagen, Denmark.

${ }^{9}$ K. G. Foote, H. P. Knudsen, G. Vestnes, R. Brede, and R. L. Nielsen, "Improved calibration of hydroacoustic equipment with copper spheres," Coun. Meet. Int. Coun. Explor. Sea 1981/B:20, Copenhagen, Denmark.

${ }^{10} \mathrm{~K}$. G. Foote, "Optimizing copper spheres for precision calibration of hydroacoustic equipment," J. Acoust. Soc. Am. 71, 742-747 (1982).

${ }^{11} \mathrm{~K}$. G. Foote, "Maintaining precision calibrations with optimal copper spheres," J. Acoust. Soc. Am. 73, 1054-1063 (1983). 
${ }^{12}$ E. J. Simmonds, I. B. Petrie, F. Armstrong, and P. J. Copland, "High precision calibration of a vertical sounder system for use in fish stock estimation," Proc. Inst. Acoust. 6(5), 129-138 (1984).

${ }^{13} \mathrm{O}$. Nakken and K. Olsen, "Target strength measurements of fish," Rapp. P. -v. Réun. Cons. Int. Explor. Mer. 170, 52-69 (1977).

${ }^{14} \mathrm{~K}$. G. Foote and $\mathrm{O}$. Nakken, "Dorsal aspect target strength functions of six fishes at two ultrasonic frequencies," Fisken og Havet, Ser. B 1978 (3), $1-95$.

${ }^{15}$ J. J. Traynor and J. E. Ehrenberg, "Evaluation of the dual beam acoustic fish target strength measurement method," J. Fish. Res. Board Can. 36, 1065-1071 (1979).

${ }^{16} \mathrm{C}$. S. Clay and B. G. Heist, "Acoustic scattering by fish-Acoustic models and a two-parameter fit," J. Acoust. Soc. Am. 75, 1077-1083 (1984).

${ }^{17}$ K. G. Foote, "Rather-high-frequency sound scattering by swimbladdered fish," J. Acoust. Soc. Am. 78, 688-700 (1985).

${ }^{18}$ K. G. Foote, "Effects of fish behavior on echo energy: The need for measurements of orientation distributions," J. Cons. Int. Explor. Mer. 39, 193-201 (1980).

${ }^{19}$ K. G. Foote, "Averaging of fish target strength functions," J. Acoust. Soc. Am. 67, 504-515 (1980).

${ }^{20} \mathrm{~K}$. Olsen, "Orientation measurements of cod in Lofoten obtained from underwater photographs and their relation to target strength," Coun. Meet. Int. Coun. Explor. Sea 1971/B:17, Copenhagen, Denmark.

${ }^{21}$ J. E. Carscadden and D. S. Miller, "Estimates of tilt angle of capelin using underwater photographs," Coun. Meet. Int. Coun. Explor. Sea 1980/ H:50, Copenhagen, Denmark.

${ }^{22}$ U. Buerkle, "First look at herring distributions with a bottom referencing underwater towed instrumentation vehicle 'BRUTIV,' " FAO Fish. Rep. (300), 125-130 (1983).

${ }^{23}$ K. G. Foote, "Linearity of fisheries acoustics, with addition theorems," J. Acoust. Soc. Am. 73, 1932-1940 (1983).

${ }^{24} \mathrm{~K}$. Olsen, "Observed avoidance behavior in herring in relation to passage of an echo survey vessel," Coun. Meet. Int. Coun. Explor. Sea 1979/B:18, Copenhagen, Denmark.

${ }^{25} \mathrm{~K}$. Olsen, "The significance of fish behavior in the evaluation of hydroacoustic survey data," Coun. Meet. Int. Coun. Explor. Sea 1981/B:22, Copenhagen, Denmark.

${ }^{26}$ R. J. Urick, Principles of Underwater Sound (McGraw-Hill, New York,
1975), 2nd ed.

${ }^{27} \mathrm{C}$. S. Wardle, "Fish reactions to towed fishing gears," in Experimental Biology at Sea, edited by A. G. MacDonald and I. G. Priede (Academic, London, 1983), Chap. 4, pp. 167-195.

${ }^{28} \mathrm{~A}$. Hylen, T. Jakobsen, O. Nakken, and K. Sunnanå, "Preliminary report of the Norwegian investigations on young cod and haddock in the Barents Sea during the winter 1985," Coun. Meet. Int. Coun. Explor. Sea 1985/ G:68, Copenhagen, Denmark.

${ }^{29}$ J. E. Ehrenberg, T. J. Carlson, J. J. Traynor, and N. J. Williamson, "Indirect measurement of the mean acoustic backscattering cross section of fish," J. Acoust. Soc. Am. 69, 955-962 (1981).

${ }^{30} \mathrm{~J}$. J. Traynor and N. J. Williamson, "Target strength measurements of walleye pollock (Theragra chalcogramma) and a simulation study of the dual beam method," FAO Fish. Rep. (300), 112-124 (1983).

${ }^{31} \mathrm{~J}$. J. Traynor, "Dual beam measurement of fish target strength and results of an echo integration survey of the eastern Bering Sea walleye pollock (Theragra chalcogramma)," Ph. D. thesis (University of Washington, 1984).

${ }^{32}$ E. Ona, "Mapping the swimbladder's form and form-stability for theoretical calculations of acoustic reflection from fish," $\mathrm{Ph}$. D. thesis (University of Bergen, 1982), in Norwegian.

${ }^{33} \mathrm{E}$. Ona, "In situ observations of swimbladder compression in herring," Coun. Meet. Int. Coun. Explor. Sea 1984/B:18, Copenhagen, Denmark. ${ }^{34}$ Report of the 1983 planning group on ICES-coordinated herring and sprat acoustic surveys," Coun. Meet. Int. Coun. Explor. Sea 1983/H:12, Copenhagen, Denmark.

${ }^{35}$ P. Degnbol, H. Lassen, and K. -J. Stæhr, "In situ determination of target strength of herring and sprat at $38 \mathrm{kHz}$ and $120 \mathrm{kHz}$," Dana 5, 45-54 (1985).

${ }^{36} \mathrm{H}$. Lassen and K. -J. Stæhr, "Target strength of Baltic herring and sprat measured in situ," Coun. Meet. Int. Coun. Explor. Sea 1985/B:41, Copenhagen, Denmark.

${ }^{37} \mathrm{~S}$. T. Forbes, "Progress in dual-beam target-strength measurement on herring and blue whiting," Coun. Meet. Int. Coun. Explor. Sea 1985/ B:22, Copenhagen, Denmark.

${ }^{38}$ M. Aksland, "Basic echo-trace-length statistics," Coun. Meet. Int. Coun. Explor. Sea 1985/B:32, Copenhagen, Denmark. 